\title{
ERRATUM
}

Nancy A. Schellhorn · David A. Andow

\section{Response of coccinellids to their aphid prey at different spatial scales}

Published online: 5 October 2005

(C) The Society of Population Ecology and Springer-Verlag Tokyo 2005

\section{Popul Ecol (2005) 47:71-76}

In Table 2, unnecessary words appeared in two entries in column 1. "Grid plot*plant" should read "Plot*plant," and "Rid error" should read "Error." The correct table appears here.

Table 2 Homogeneity-of-slopes model for the effect of aphids at the plant and plot scale on $C$. maculata and $H$. convergens adult density

\begin{tabular}{lrlrl}
\hline Source & df & MS & $F$ & $P$ \\
\hline C. maculata & & & & \\
Plot & 38 & 0.5599 & 1.46 & 0.0002 \\
Plant & 1 & 0.6565 & 1.71 & 0.1919 \\
Plot*plant & 38 & 0.5878 & 1.53 & 0.0241 \\
Error & 597 & 0.3845 & & \\
H. convergens & & & & \\
Plot & 38 & 0.1199 & 0.81 & 0.7832 \\
Plant & 1 & 1.5524 & 10.51 & 0.0013 \\
Plot*plant & 38 & 0.2430 & 1.65 & 0.0098 \\
Error & 598 & 0.1477 & & \\
\hline Aphid & & & &
\end{tabular}

Aphid density was log-transformed

The online version of the original article can be found at http:// dx.doi.org/10.1007/s10144-004-0204-x

N. A. Schellhorn · D. A. Andow

Department of Entomology, University of Minnesota, Saint Paul, MN 55108, USA

N. A. Schellhorn $(\bowtie)$

CSIRO Entomology, 120 Meiers Road,

Indooroopilly, QLD 4068, Australia

E-mail: nancy.schellhorn@csiro.au

Tel.: + 61-7-32142721

Fax: +61-7-32142885 